\title{
Humanismo, humildade e sabedoria
}

Emmaiodeste ano, oprof. Isaac Nicolau Salum deixou-nos para entrar no Panteão das Letras de nossa Faculdade de Filosofia, onde certamente o estavam esperando os amigos Tonioli, Maurer e Aubreton. Que falta nos fazem esses quatro humanistas e é pena que as novas geraçōes nāo possam conhecê-lospessoalmente! Privilegiadosou eu, que fui aluno do prof. Theodoro Maurer Jr., em Filologia Românica e Glotologia Clássica (quando me iniciei em sânscrito), do prof. Armando Tonioli, em Língua e
Literatura Latina, doprof. Robert Aubreton, em Língua e Literatura Grega, e do prof. Isaac Nicolau Salum, em Filologia e Lingüística Românica, nocursode Letras Clássicas, de 1957 a 1960, ainda na antiga Faculdade de Filosofia, Ciências e Letras, no heróicoprédio da rua Maria Antônia, ícone da resistência cultural e política dos anos 60. E, se a Faculdade de Filosofia foi (e espero que ainda seja) o espaço da resistência, bem como o centro da reflexāo, da crítica e da produção do saber, ícone enfim da
IZIDORO BLIKSTEIN é professor de Semiótica e Lingưistica Geral da FFLCH-USP. 
própria Universidade de São Paulo, o prof. Salum é, por sua vez, um dos ícones mais representativosdaFaculdade na medida em que soube encarnar o melhor da missão crítica, formadora e humanista da Universidade. Não seria exagero dizer que o prof. Salum foi, até certo ponto, o "rosto" da Faculdade de Filosofia, e falar dele é falar um pouco de todos aqueles que fizeram $e$ fazem viver a nossa alma mater.

Mas... o que falar do prof. Salum? A sua passagem pela Faculdade foi tăo exuberante que talvez não caiba num depoimento limitado como este e deva, na verdade, ser matéria de uma dissertação de mestradoou, melhor ainda, de uma pesquisa que conduza a uma tese de doutorado. Vou, portanto, ater-me a alguns aspectos de sua atuação como professor, pesquisador e como ser humano, irradiando um exemplo de sabedoria e humildade a servir de guia para todos os que querem aventurar-se pelas veredas do magistério. Tenho a certeza, contudo, de que o prof. Salum retrucaria, declarando categoricamente: "Eu não sou nem fui nada disso" (1).

Mas, a tal declaração, eu responderia, citando um companheiro de correspondência do prof. Salum, e também seu coestaduano, o poeta Carlos Drummond de Andrade: "Faço mil coisas/que criarâo outras mil, aqui, além, nos Estados Unidos" ("Morte no Aviâo").

E quantas coisas não terá feito o prof. Salum? Aulas, conferências, orientação, conversas, conselhos, estímulos, artigos, teses, palestras, mais aulas, mais conselhos, mais orientação, mais conversas, contínuas e infatigáveis pesquisas, enfim..., a inteireza de uma vocação como professor. Mas que tipo de professor foi Isaac Nicolau Salum?

Bem, sabemos que o magistério pode ser um exercício de poder, em que o mestre é o sujeito detentor do saber e o aluno, o "objeto que não sabe" (um "depósito vazio", no dizer de Paulo Freire). Outra foi a postura do prof. Salum. Em suas aulas e orientaçōes, os alunos eram sujeitos participantes do processo do conhecimento e da busca da verdade científica, estimuladosque eram por uma relação de horizontalidade $\mathrm{e}$ não oprimidos por um autoritarismo vertical. Tal relação de horizontalidade, que dissolvia barreiras e inibiçōes e permitia a criação de um clima de descontração indispensável à pesquisa científica, devia-se certamente a algumas atitudes metodoló- gicas (e sobretudo ideológicas) do prof. Salum como:

1) Despojar-se de análises pedantes e pretensiosamente científicas, procurando, antes de tudo, auscultar o texto, deixá-lo "falar" e extrair as intermináveis liçōes que ele pode nos oferecer. Esse procedimento filológico (é bom lembrar que, etimologicamente, o filólogoé "o amigo do texto") não está longe da semiose infinita, de que nos fala Umberto Eco, ao aludir às múltiplas possibilidades de leitura dos signos.

2) Levar os alunos a desconfiar da percepçāo linear e estereotipada de um texto, conduzindo-os a uma visão estrutural e "icônica", por meio de uma técnica de desmontagem e remontagem sintáticoestilístico-semântica. Trata-se de uma verdadeira anatomia do texto, como foi o caso - apenas para citar dois, dentre as centenas de textos "remontados" pelo prof. Salum dos poemas "Marabá", de Gonçalves Dias, e de "No Meio do Caminho", de Carlos Drummond de Andrade: a "fotografia" sintático-estilística dos poemas nos leva a enxergar Gonçalves Dias e Drummond com novos olhos (2) (ver os Anexos I e II). A origem desse método de reorganização lingüístico-retórica do texto nos é contada pelo prof. Salum, numa passagem em que se evidenciam não só a humildade e a probidade científicas, mas também a preocupação humanística com a clareza do método:

"Em 1944, numa classe do $2^{2}$ clássico, tive de enfrentar um período complexo latino de 19 hexâmetros (Geórgicas, I, 24-42): é a parte final da 'invocação', que ali assume ares de 'dedicatória' e por isso Camổes a tomou por modelo para fazer a sua 'dedicatória' d'Os Lusíadas. Overso 24 começa por Tuque adeo, seguem-se duas oraçōes incidentes, o verso 25 retoma, no fim, Caesar, retornam as incidentes, até os vv. 40-42, que retomam a oração independente múltipla, iniciada no v. 24. Os alunos nãopuderam seguire eume desarvorei. Resolvi então buscar um meio, se não de desfolhar a árvore dotexto, de tornála transparente, deixando ver ao mesmo tempo o conjunto de galhos (grifos meus). Nasceu assim um método de visualização das linhas mestras do texto, que eu chamei de fórmula de constituiçāo do texto, outras vezes radiografia do texto, mas só aplicando o proces- 


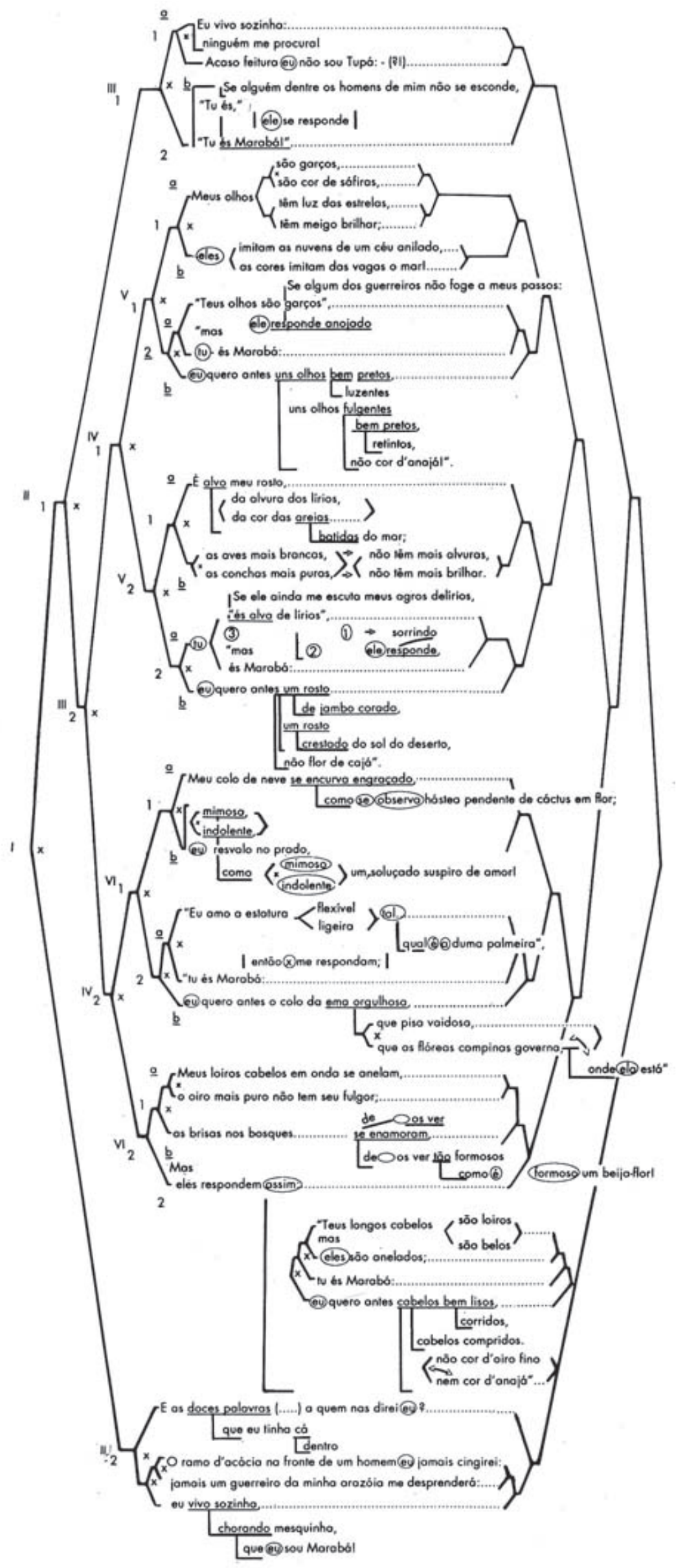



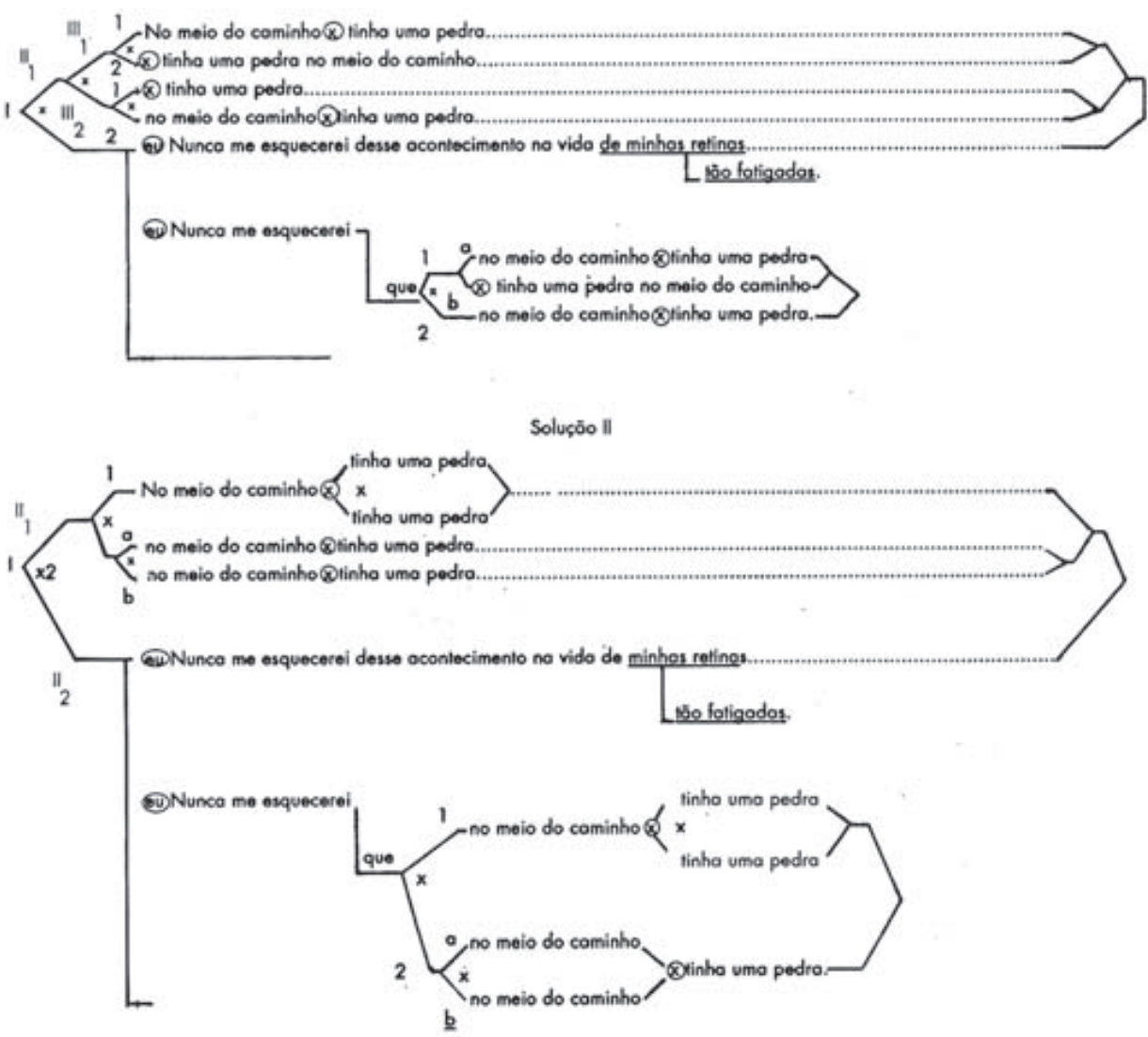

so ao período oratório na prosa ou no verso, para o latim, e depois também para o português.

Chamo-o hojeAbordagem LingüísticoRetórica do Texto e aplico-o também aos textos simples, só de pequenas frasescoordenadas, e a experiência me vem mostrando que muitas vezes são esses os que mais problemas oferecem" (3).

Para avaliar a repercussão interdisciplinar da abordagem lingüistico-retóri$c a$, ouçamos o que dizem a respeito os professores Antonio Candido e Segismundo Spina, dois expoentes da Universidade, respectivamente da área de Teoria Literária e da área de Filologia e Língua Portuguesa:

“... num campo ele desamarrou: o da análise lingüístico-literária. Talvez porque os garfos e esquemas que inventou possuam um vago ar de quebra-cabeça, que, introduzindocerta atmosfera lúdica, parece atenuar o compromisso com o rigor e permitir maior liberdade. De qualquer modo, aí ele atua com desafogo e prazer, oferecendo largamente os resultados da sua desmontagem minuciosa, paciente e cheia de iluminações, que permite mostrar com segurança a anatomia e a mensagem dos textos. Sem bulha nem matinada, foi construindoum método original, preciso e fecundo, que ainda por cima tem a vantagem de projetar-se numa figura que o olhar abrange, dispondo o texto conforme a arquitetura do sentido real" (4).

“... aí por volta de 1965 , começaram a circular, entre os colegas da Faculdade de Filosofia, os gráficos de análise de textodoprof.Salum, altura em que a sua técnica amadurecia em método, conquistando aos poucos a adesâo dos colegas, que de início enxergavam apenas nos seus gráficos um esquema decorativo, à guisa de arabesco... A distribuição dos esquemas foi aumentando, e gradativamente conquistando a curiosidade e o interesse de uma clientela que passou a acreditar nas novidades do sistema, pois ele superava o velho e acanhado método da análise lógica, abrindo novos horizontes na inteligência lingüística do texto, cujos valores semânticos, estilísticos, retóricos - e, por que não dizer, a própria maneira de os autores visualizaremomundo-eram desconhe- 
cidos completamente pela abordagem sintática tradicional.

Salum arrebentava de alegria quando percebia que seus esquemas eram examinados, estudados e às vezes até contestados pelos colegas. Não raro os gráficos eram redistribuídos em $2^{\mathrm{a}} \mathrm{e}$ até $3^{\mathrm{a}}$ ediçāo, pois o próprio autor muitas vezes se dava conta das imperfeiçōes ainda existentes nos seus esquemas, ou acatava as opiniōes divergentes que lhe pareciam válidas" (5).

Além da irradiação do método, esses comentários ilustram sobretudo a figura intelectual e humana do prof. Salum, o seu rigor científico, o seu entusiasmo e a sua modernidade.

3) Desconfiar de modismos e de supostas novidades. Embora desenvolvesse uma leitura atenta e atualizada dos mais importantes autores da lingüústica contemporânea (Saussure, Hjelmslev, Benveniste, Martinet, Jakobson, etc.), colaborando na traduçãodemuitos deles(Benveniste, Lyons e, particularmente, o Dictionnaire de Linguistique, de J. Dubois) ou introduzindo-os com brilhantes prefácios (Saussure), oprof. Salum não deixava de lado a lingüística histórica e diacrônica, realizando um saudável vaivém entre o "tradicional" e a modernidade, com um invejável conhecimento dos textos clássicos e das línguas antigas (grego, latim e hebraico). Éo que se pode verificar à saciedade em dois autênticos monumentos de erudição e perspicácia lingüística (infelizmente, ainda inéditos), a saber: A Semana Astrológica e a JudeuCristã. Introduçāo à Problemática da Nomenclatura Semanal Românica, São Paulo,FFCL/USP, 1967, tese de livre-docência; AProblemática da Nomenclatura Semanal Românica, São Paulo, FFLCH/USP, 1968, tese de cátedra.

Nesses e em outros trabalhos do gênero, há uma verdadeira escavação pelos textos antigos, em que o prof. Salum demonstra a atualidade do "tradicional" e confirma a sábia advertência do lingüista E. Coseriu, para quem a história da lingüística é cheia de ocos e, por desconhecimento da história das idéias sobre a linguagem, freqüentemente "descobrimos" conceitos e pensamentos que já tinham sido formulados no passado. Assim, num primor de artigo que é "AsVicissitudesdos Dêictico-anafóricos", o prof. Salum recupera considerável parte da história dos gramáticos, filólogos e lin-

güistas que trataram dos pronomes, e estabelece uma ponte luminosa entre o antigo e o contemporâneo. Esse trabalho é uma lição de método e de postura científica a ser lido por todos nós que, muitas vezes, nos empolgamos com autores e teorias aparentemente novos, mas que, no fundo, sāo tributários de todo um caudal de reflexões disseminadas numa intertextualidade a ser resgatada desde a antigüidade clássica. Note-se com que graça e sapiência o prof. Salum conclui o artigo:

\begin{abstract}
"Aí está oque se pôde realizar do que foi prometido. Se o problema tivesse ficado mais claro ao meu espírito, este estudo teria saído mais breve. Houve necessidade de citar textos não muito acessíveis, de traduzir outros não muito inteligíveis. Espero que, se a leitura deste texto chegar a cansar, não tenha sido muito entediante nem seja considerada como pura perda de tempo, e, sobretudo, que alerte o leitor para que não chamedesdenhosamente "tradicional" oque nos vem do passado nem proclame afoitamente como "descoberta nova" o que o passado já tinha visto ou entrevisto. Toda cultura tem vicissitudes, nãosó os pronomes. Repensar a História é aprender da vida" (6).
\end{abstract}

4) Encarar a ciência e a própria universidade com uma atitude "brechtiana" de estranhamento. Utilizando a história, a etimologia e o conhecimento seguro dos fatos lingüísticos, oprof. Salum nos ensinava a reagir com humor e distanciamento crítico a algumas situaçōes típicas do contexto universitário; assim, quando um colega

“... ao falar em gramáticos e filólogos, com uma pontinha de desdém, olhava para o meu lado e sorria, eu protestei, mas foi 'de mentira' ou, antes, foi mesmo 'de verdade', porque, infelizmente, não sou nada disso. Gramático é palavra derivada de gramma, 'letra', deverbal de grapho, 'escrever': gramático é o que mexe com os textos. Filólogo, de philólogos, é o 'amigo das palavras', 'amigo da cultura e da literatura', 'estudioso' (cf. o inglês scholar), 'amigo dos livros', o 'erudito' (o savant dos franceses), 'o amigo do texto'. Os chamados 'Gramáticos Alexandrinos' eram isso: leitores, editores, anotadores,
5 S. Spina "Humilitas ot Sapientia", in Estudos de
Filologia $\theta$ Linguística, T. A. Queiroz Editor/Edusp. São Paulo, 1981, pp. 305-6.

6 I. N. Salum, "As Vicissitudes dos Deictico-anafóricos", in in do Paula FFLCHes Simáes Paulo, 1983, p. 342. 
críticos, de Homero, de Hesíodo, dos outros poetas gregos. Por isso, refletiam sobre a língua dos textos, e daí é que vieram os gramáticos. Dionísio, Trácio e Apolônio Díscolo, gregos que os latinos seguiram e que Prisciano, sobretudo, conservou. Tudo saiu do estudo dos textos" (7).

5)Estar disponível, dentro mas também fora do espaço da sala de aula. Sem nenhum formalismo, o prof. Salum conversava e trocava idéias sobre fatos lingüísticos com qualquer pessoa (não necessariamente o aluno "oficial"), independentemente da condição social, do momento ou do lugar. Para o prof. Salum, todo ser humano pode produziruma "ciência" lingüística:para tal, é preciso que sejamos atentos observadores, com sensibilidade e memória atiladas, capazes de saber perceber, registrar e interpretar a contínua produção de fatos lingüísticos por parte do falante.

Vale apreciar com que graça literária, $\mathrm{e}$ com que afeto, o nosso Mestre trata de um episódio lingüístico ocorrido em sua infância:

"Nasci em 1913, e passei meus primeiros dezessete anos de vida num arraial do sul de Minas, chamado oficialmente São Sebastião da Ventania, e por nós Ventania, mas que passou a chamar-se, em setembro de 1914,Alpinópolis, sem qualquer semelhança com os Alpes. Complexos de inferioridade de um arraial, cuja grande aspiraçāo era tornarsevila. O Abrāo Turco-um maometano local, de altoporte e barbas grandes, cuja lembrança hoje me faz pensar no 'Moisés' de Miguel Ângelo, apostava céptico: 'Se Bentania bira de bila, Abrão bira de cabalo'. Pois veio a vitória: em 17/XII/1938, passou o meu arraial a cidade, a comarca, e hoje tem três ou quatro grupos escolares e um ginásio estadual, e mantém, no seu município, a hidrelétrica de Furnas, que manda luz para São Paulo" (8).

Essa figura exemplar de professor foi também marcada por uma série de iniciativas, tarefas e atitudes, tais como:

7 "Depoimento... p. 202

8 "Depoimento.... p. 192.

9 "Apresentaça", in Estudos de Filologia • Linguistica, p. 3.

$10^{\circ}$ O Primo", in Estudos, p. 301.
São Paulo (GEL).

b) Criação do curso de Romeno na FFLCH, concretizando a sábia recomendação do prof. Theodoro Maurer Jr., ao defender a importância do estudo do Romeno para um conhecimento mais seguro e abrangente da Lingüística Românica.

c) Incansável orientaçāo de alunos de pósgraduaçāo, "a qualquer hora do dia ou da noite", e participaçâo efetiva em mais de uma centena de bancas de mestrado, doutorado, livre-docência, de concursos para titular, etc., sempre contribuindo com minuciosas e inúmeras observaçōes críticas, rigorosamente anotadas nos textos dos trabaIhos avaliados. Éoportuno transcrever aqui um trecho da "Apresentação" de Estudos de Filologia e Lingüística, coletânea feita em homenagem ao prof. Salum:

“É impossível avaliar a extensão dessa atividade, pois ela nãorende artigos nem livros. Mas a Lingüística Românica e Portuguesa não seria a mesma - sobretudo no estado de São Paulo - não fossem assuasatividades, lendominuciosamente os trabalhos que lhe são submetidos, reescrevendo traduçōes de obras de porte, e achando sempre tempo para ajudar quem o procura" (9).

d) Participação política, não só "amargando" com a Universidade o triste e obscuro período da ditadura militar, mas também, no dizer de Antonio Candido, manifestando indignaçãoe "estrilos oportunos quando os princípios estāo em jogo" (10).

Para concluir este depoimento, gostaria de apresentar aqui um texto inédito que constitui um testemunho vivo da figura humana e intelectual do prof. Salum. Já foi dito aqui e freqüentemente é reiteradoo fato de que a trabalhosa atividade crítica do Mestre, ao julgar e comentar pacientemente monografias e teses, não lhe rendeu publicaçōes. Talvez, por isso, vale transcrever uma pequena amostra dessas anotaçöes, pois dificilmente serão publicadas, uma vez que se encontram espalhadas por essa mais de uma centena de trabalhos que o prof. Salum argüiu e criticou. Em 1973, tive a honra de defender a minha tese de doutoramento, Perspectivas da Etimologia para o Estudo Etimológico-semânticoda Família deKára, perante uma banca memorável, formada pelos professores Isaac Nicolau Salum (orientador), Theodoro Maurer Jr., Robert Aubreton, José Cavalcante e Francisco da 


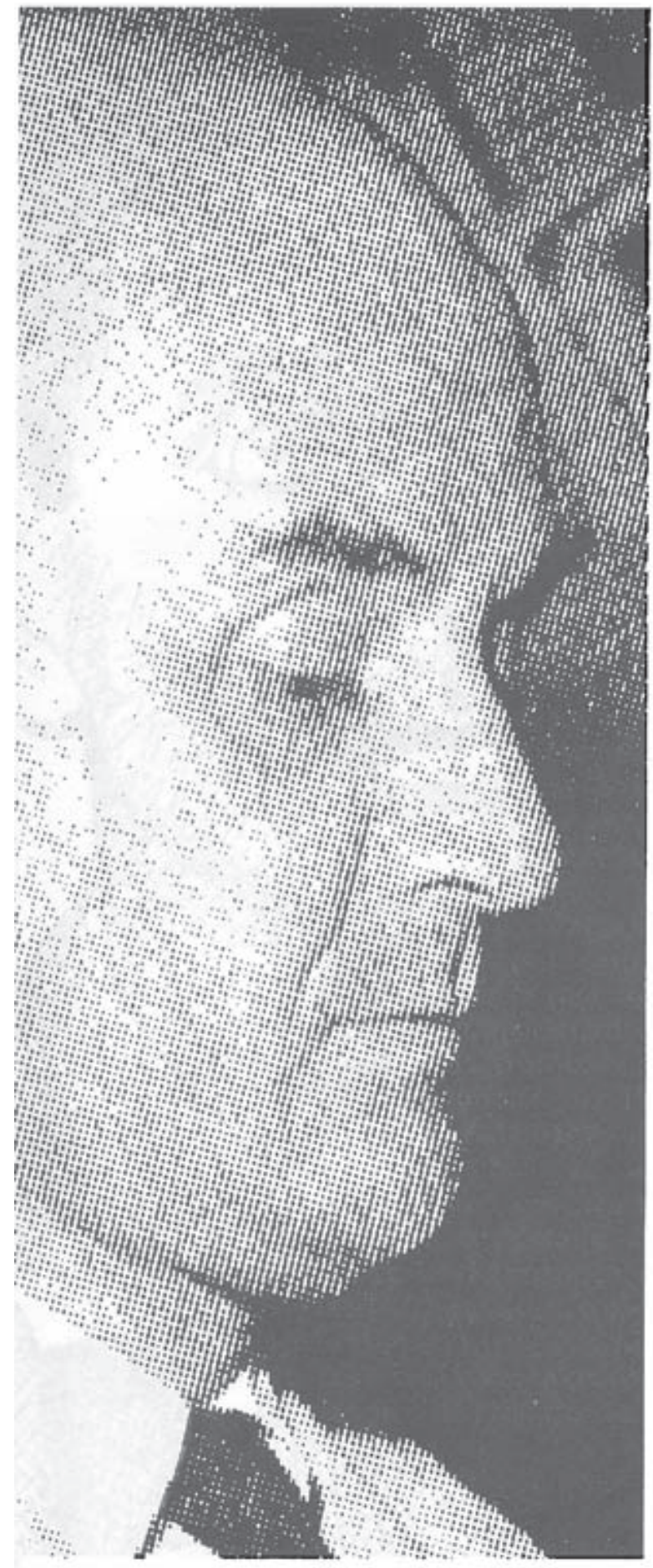

Silva Borba. Depois de árdua defesa, recebi das mãos do prof. Salum o seu exemplar, comaproximadamente umas 250 anotações: eram críticas e observaçōes perspicazes sobre problemas de forma e de conteúdo. Guardo-as carinhosamente e sempre volto a elas quando batem as saudades ou quando quero dar uma liçāo de método e de bom senso a algum orientando. Pois bem, dentre essas anotaçōes todas, feitas com paciente labor e...com afeto, há uma que certamente fala por si, ilustrando para as novas geraçōes o perfil inteiro do prof. Salum: humanista, humilde e sábio. Vou contextualizar a referida anotação. A certa altura da tese, para defender a importância dos estudos clássicos, citei, como apoio, as ponderaçōes do prof. Salum e do prof. Aubreton - a quem chamei humanistas - $\mathrm{e}$ que ora transcrevo:

“... (a explicação dos dias da semana) não mata fome de alimentos nem satisfaz a ambição de possuir um aparelho ou um carro, nem mata um inimigo na guerra, nem nos leva à Lua ou a Marte mas trará Marte, a Lua e atéSaturno, nos nomes dos dias, à nossa convivência semanal e diária...” (11).

"Omelhor engenheiro, o melhor químico, o melhor físico, não será somente aquele que acumular inúmeros conhecimentos: será essencialmente um homem que tiver consciência do valor do homem, que for capaz de ir além de seus conhecimentos materiais. Terá de lutar contra a matéria e o materialismo que o envolve. Será somente capaz de fazê-lo depois de ter recebido uma formação profunda, de tertidocontatoestreitocom o pensamento dos homens de todos os tempos e de todas as latitudes..." (12).

E aqui deixo para o leitor saborear a anotação crítica (verso da p. 74 de minha tese), em que o querido prof. Salum, ao protestar contra o epíteto humanista, a ele aplicado, permite-nos desenhar a inteireza de sua figura humana e intelectual, mais do que nunca viva entre nós, com a sua humanidade, mas sobretudo com a sua generosidade e a sua grandeza de espírito:

"Se o prof. Aubreton é um humanista, eu não posso ser posto junto: ele é um nome europeu, eu sou apenas um professorzinho brasileiro, que, especialmente nestes últimos anos, só estudo um pouco de teimoso.

De qualquer maneira, se as minhas 'tolices' não o escandalizaram, eu lhe agradeço a complacência".

Não, prof. Salum, nós é que lhe agradecemos por tudo o que o senhor fez pela Faculdade, pela Universidade e pela cultura brasileira.
111.N. Salum, A Problemítica de Nomenclatura Semanal Ro mánica, SÅo Paulo, FFLCH. USP, 1968, p. VIII.

12 R. Aubreton, "O que Poderia Ser a Polísica Cultural do Es. tado de SAso Paulo", in Bolo im do Estudos Clisssicas, 